DEPARTMENT OF THE INTERIOR

U.S. GEOLOGICAL SURVEY

\title{
Embedment, penetration, hole closure, and related geotechnical tests associated with subseafloor nuclear waste disposal
}

by

William J. Winters 1

Open-File Report $87-256$

This report is preliminary and has not been reviewed for conformity with U.S. Geological Survey editorial standards and stratigraphic nomenclature. Any use of trade names is for descriptive purposes only and does not imply endorsement by the USGS.

1 Woods Hole, Massachusetts 02543 


\author{
DEPARTMENT OF THE INTERIOR \\ UNITED STATES GEOLOGICAL SURVEY
}

\title{
EMBEDMENT, PENETRATION, HOLE CLOSURE, AND RELATED GEOTECHNICAL TESTS ASSOCIATED WITH SUBSEAFLOOR NUCLEAR WASTE DISPOSAL
}
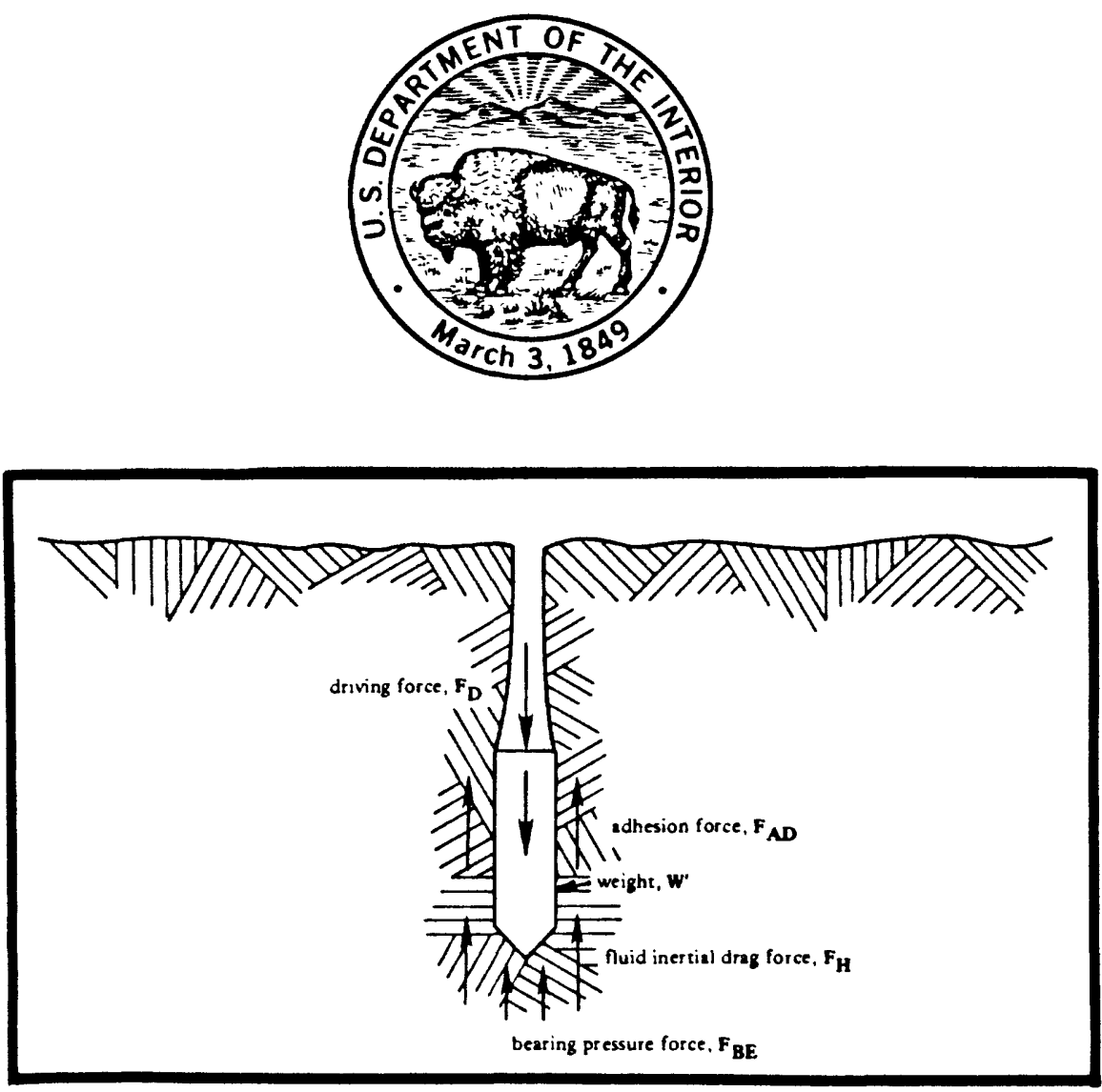

Open-File Report 87-256

May 1987

This report is preliminary and has not been reviewed for conformity with U.S. Geological Survey editorial standards and stratigraphic nomenclature. Any use of trade names is for descriptive purposes only and does not imply endorsement by the USGS. 


\section{ABSTRACT}

This report examines some of the factors involved with disposal of both high-level and low-level radioactive waste beneath the seafloor. Topics covered include: (1) seafloor sediment properties, which relate to free-fall emphasized methods of disposal; (2) techniques for predicting embedment or penetration from free-fall of low-level and high-level waste; (3) hole closure behind a penetrating cannister; and (4) geotechnical testing required to predict free-fall penetration depths.

\section{INTRODUCTION}

Although numerous plans have been proposed to safely dispose of the radioactive products generated by many industrial and government sources within the United States and throughout the world, unanimous endorsement of any one method has not yet occurred. Some locations on land where low-level nuclear waste was previously buried have not provided anticipated environmental protection (Fischer, 1986). In place of or in addition to disposal sites on land, the seafloor presents other options for storing waste (Manheim and Vine, 1986; Hunsaker and Kelly, 1987).

Because hundreds of thousands, even millions, of years may be required to reduce high-level radioactivity of the wastes to non-harmful levels and the container itself will leak during that time period, geologically stable areas must be chosen for disposal (Hollister, 1977; Heath, 1977). In addition, the heat produced by the waste could affect the sediment surrounding the cannister.

One method suggested for disposal of high-level nuclear waste that may not be affected by those problems is to implant cannisters of the material into abyssal plains far from population centers, land masses, and geologically unstable areas. Abyssal plains are large, flat areas of the seafloor; they are generally located between the continental rise and abyssal hills (Fig. 1), and are comprised of sedimentary deposits such as pelagic clays or turbidites as much as $2000 \mathrm{~m}$ thick. It is believed that the overlying sediment cover and water column (greater than 4000 meters) would reduce the potential for immediate human contact with the waste.

Fine-grained sediment beneath the seafloor possesses characteristics favorable to nuclear waste containment, such as: low shear strength, which would thereby allow free-fall penetration by the waste containers into the sediment and subsequent closure of the holes formed by penetration; low permeability, which inhibits the migration of pore fluid and contaminants; and sorption qualities that reduce the mobility of dissolved radionuclides (Silva, 1977). However, not all abyssal plain sediments have those desirable properties; for example, relatively coarse-grained turbidites would not be effective as a host material (Fig. 2). Furthermore, some evidence indicates that some abyssal plain sediment has been fractured and faulted indicating that it may not be a geologically stable environment (Richards, 1986). Pore fluid, containing radionuclides, could migrate along those fault planes if sufficiently strong hydraulic gradients are present. 


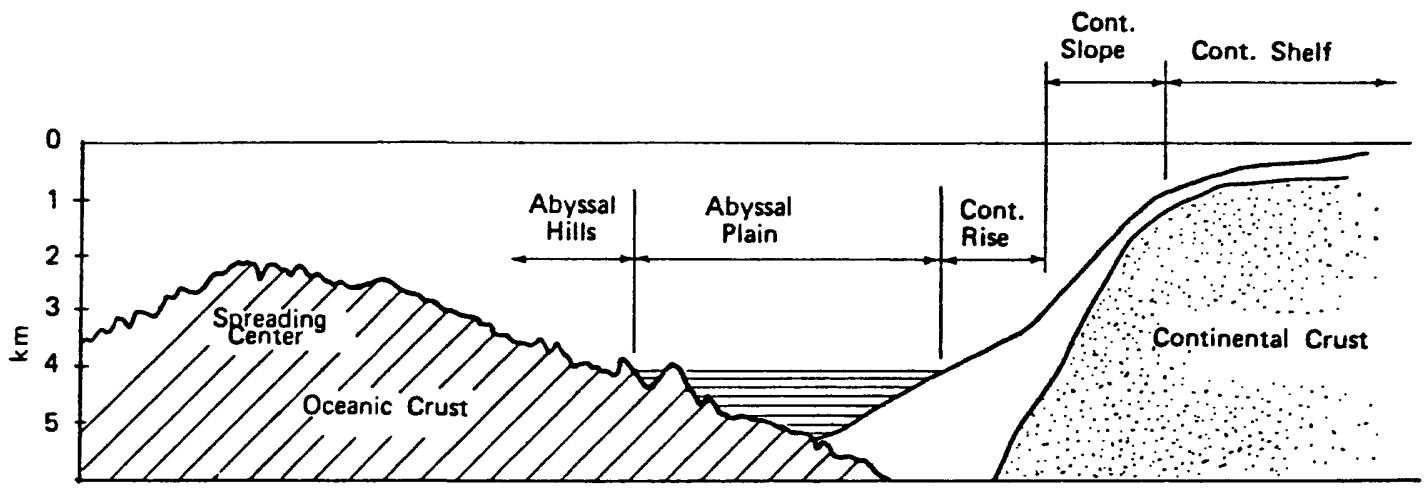

Figure 1. Generalized cross section of an ocean basin showing an abyssal plain; vertical features are greatly exaggerated (Chaney and others, in press). 


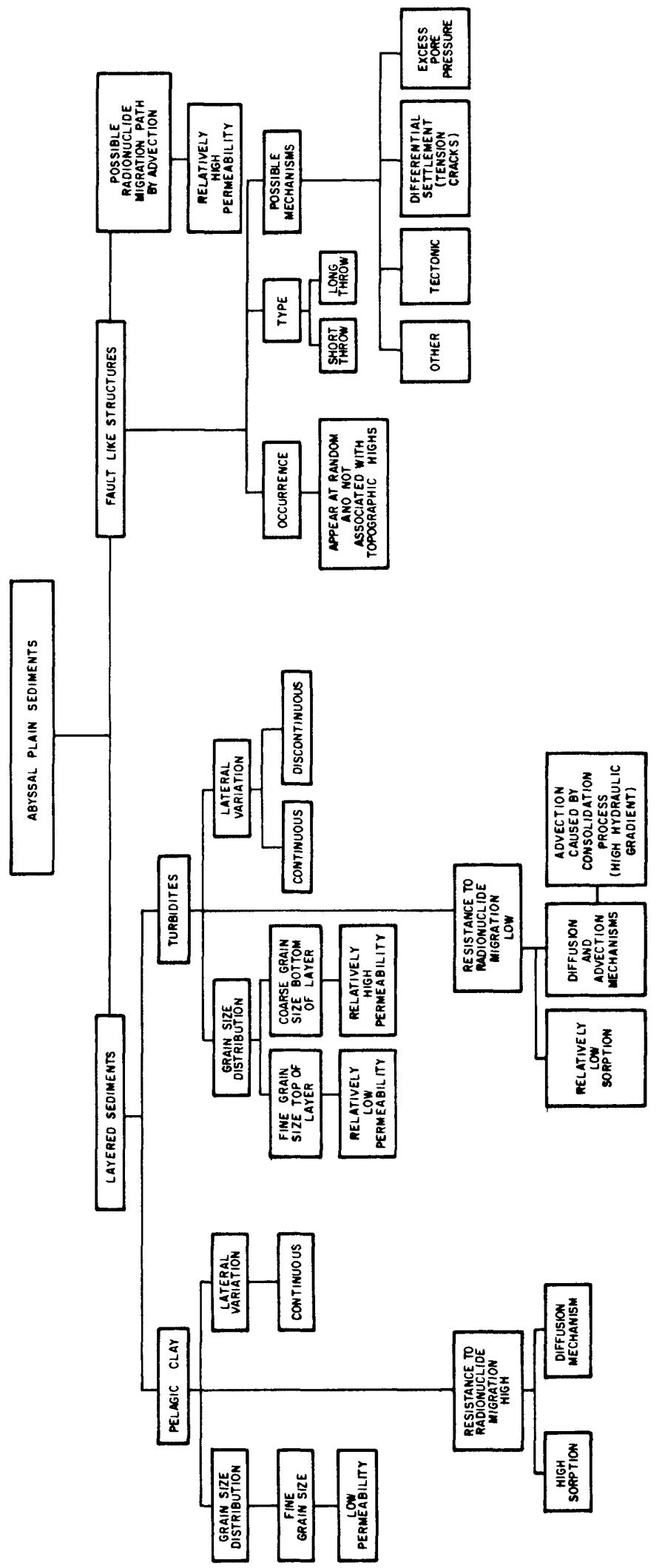

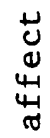

崩

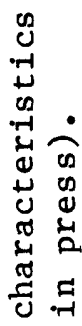

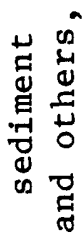

兵 常

का

के

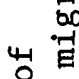

क्ष

$\underset{j}{2}$ 
Various methods have been suggested for high-level nuclear waste disposal in the seafloor. If a free-falling method is used, a streamlined wastecontaining projectile will probably be required to penetrate the necessary meters of sediment. However, adequate penetration into the seafloor is not enough; subsequent hole closure must occur in order to reduce migration of harmful substances to the water column. The partly remolded sediment will also have to possess properties that make it an effective barrier against harmful radioactive products.

Valent and Lee (1976) and Bury (1985) proposed other methods for burial, for example, static penetration by means of a heavy drive-pipe, insertion of the waste into drilled holes, or using a submarine or seafloor mole to push or pull the containers into the sediment. A number of methods and sites for high-level waste disposal have been proposed including deep-sea trench emplacement, shallow drilling into crustal rock, placement on the surface of the seafloor, and ocean dispersion. Other methods can probably be developed or modified from existing technology in addition to the previously mentioned techniques. However, none of the methods have gained unanimous acceptance.

More options are available for the disposal of low-level radioactive waste than for high-level waste because the time required for reduction of the low-level waste to less harmful products is on the order of hundreds (not hundreds of thousands) of years and heat is produced at a much lower rate. Complete burial of cannisters containing low-level waste may not be necessary; corrosion-resistant cannisters could be stored directly on the seafloor without significant threat to the biota in the surrounding sediment or water.

However, even if disposal on the surface of the seafloor were acceptable in a given environment, it would not necessarily preclude complete burial. The methods for high-level waste disposal, such as free-fall penetration with subsequent hole closure, may be applicable to low-level waste as well.

\section{PREDICTION OF PENETRATION DEPTH}

Embedment occurs if an object penetrates the seafloor but does not completely disappear within the sediment, so that some of the object remains above the seafloor. An attractive feature of embedment is that it allows inspection and retrieval of the waste material. The amount of penetration into the seafloor can be limited by disposing of containers at sites where: (1) sediment is hard, consists of gravel, or where rock surfaces are present; (2) designing the containers with a geometry that reduces impact velocity and penetration; and (3) lowering the cannister by cable in order to reduce or eliminate impact velocity. Analyses that can predict the amount of embedment of an object into the seafloor are very similar to the methods used to determine complete penetration and utilize some of the same geotechnical tests to determine sediment behavior under impact (Brian Watt Associates, Inc., 1985). Before accurate estimates of embedment depth can be made, certain sediment properties such as in situ density and undrained shear strength of fine-grained or friction angle of coarse-grained sediment have to be determined (Fig. 3). 


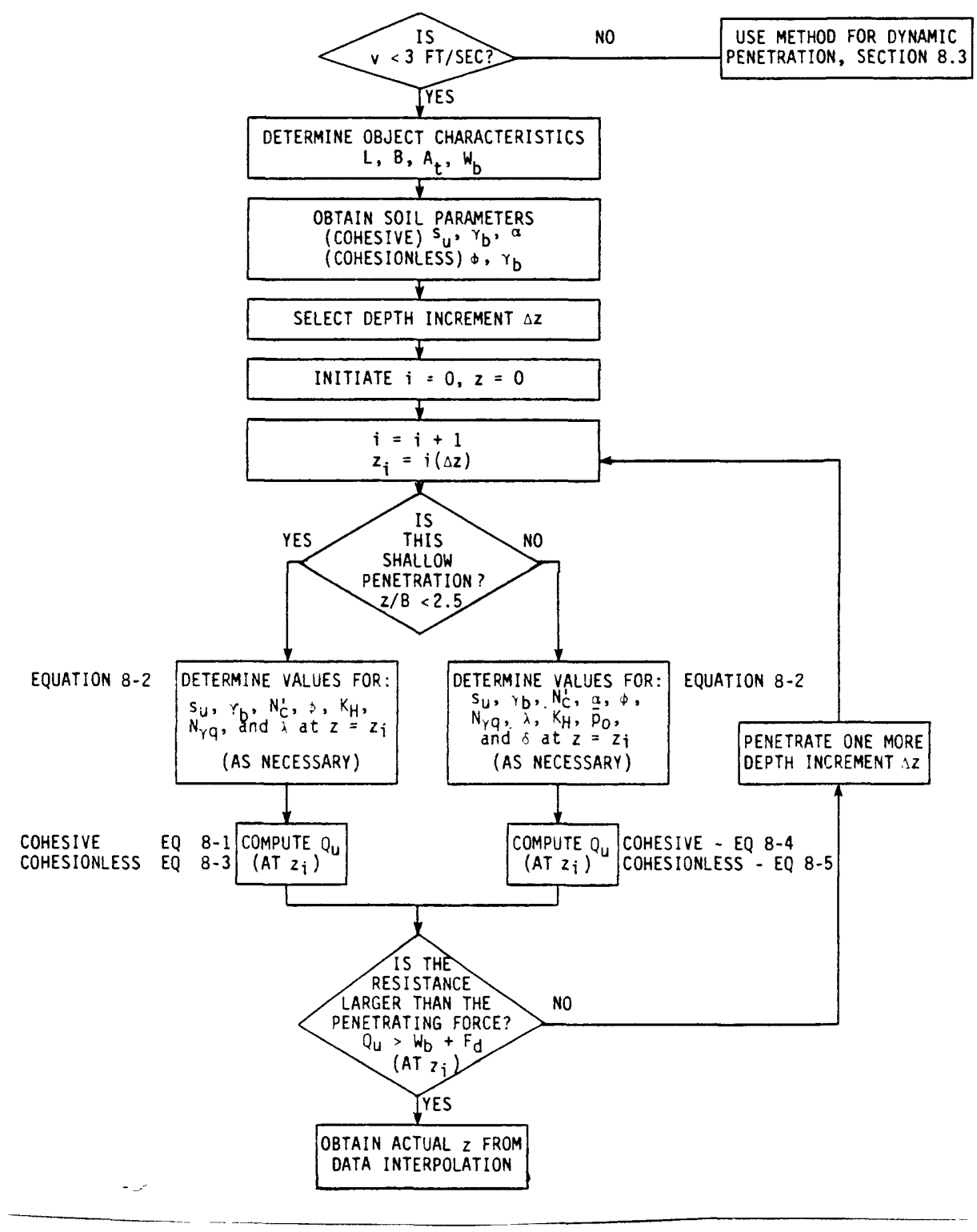

Figure 3. Flow chart of the calculation procedure for predicting static penetration (Brian Watt Assoc., Inc., 1985). 
Complete subseabed penetration, the entry of the entire projectile deep beneath the seafloor such that no part of the object protrudes above the seafloor, has been proposed as a method of high-level nuclear waste disposal and as an optional means for disposing of low-level waste. In order for penetration to be adequate and containment successful a streamlined penetrator encasing the waste should be dropped, pushed or propelled into soft sediment or drilled into hard sediment or intact rock. Two critical criteria need to be met by any of these methods: adequately deep penetration and subsequent hole closure. Free-falling a heavy penetrator is economical and should provide adequate penetration: Silva (1977) surmised that a streamlined container at a terminal velocity of $30 \mathrm{~m} / \mathrm{s}$ (about $70 \mathrm{mi} / \mathrm{hr}$ ) could penetrate more than $30 \mathrm{~m}$ into soft sediment. However, Karnes and others (1984) suggested that boosted-velocity penetrator emplacement may be necessary to reach sufficient penetration depth at typical deep-sea sites. Optima1 penetration is achieved in areas of fine-grained sediment (silts and clays). Regions that contain boulders or layers of grave1 or sand that could prevent the deepest possible penetration and that have poor "barrier" characteristics should be avoided.

The topic of subseabed penetration has been studied by a number of investigators, each making his own contribution to the state-of-the-art and proposing new assumptions with regard to sediment properties and behavior. Schmid (1969) performed an extensive and detailed investigation into the factors affecting free fall, powered travel, and dynamic penetration of objects into the seafloor. Besides presenting a method useful for determining terminal velocity, drag coefficients and penetrator shape were also addressed. Schmid states that the most important factors to be determined for an analysis of penetration depth are: (1) impact velocity, (2) mass and geometry of the penetrator, (3) trajectory of initial impact, and (4) ocean sediment properties.

True (1974) conducted four series of laboratory model tests on penetration into soft silt and soil-cement mixtures that simulate cemented soils. A stud driver gun fired various projectiles at different velocities into the soil. Sediment dynamic properties and behavior were interpreted using a modification of the Poncelet equation (Schmid, 1969, eq. 12) which states that the resisting force is dependent on a constant and a velocity squared term. True incorporated a bearing pressure force and a side adhesion force into the equation (Fig. 4). Newt on's second law of motion, which is solved incrementally, is the basis for the penetration depth calculations.

True assumed that the sediment shear strength is strain-rate dependent and presents a set of factors that can be applied to static undrained shear strength measurements of soil to account for the high penetration rates. Shear tests can be performed at various velocities on a particular sediment if better accuracy is required at a site. The accuracy of the side adhesion values can likewise be improved with specialized testing methods. By assuming a sediment sensitivity (ratio of natural undrained shear strength to remolded shear strength) equal to 3 and a typical strength profile for soft finegrained seafloor sediment, True predicted an accuracy of $\pm 50 \%$ can be obtained for the final penetration depth using his iterative method. Greater accuracy would involve performing sediment strength, sensitivity, strain-rate effect, and adhesion tests. A more extensive description of the model laboratory tests was presented in a later publication (True, 1975). 


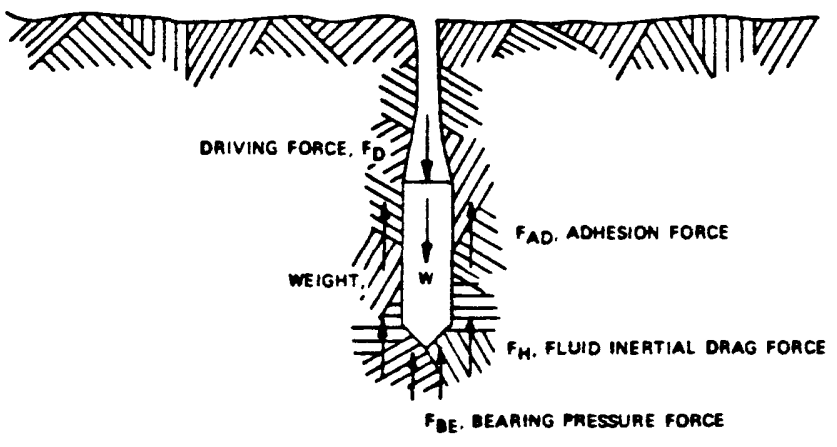

Figure 4. Forces acting on a penetrator (True, 1974). 
Three methods for long-term nuclear waste disposal beneath the seafloor (for isolation periods of up to one million years) were presented by Valent and Lee (1976): free-fall or dynamic penetration, static or constant force penetration, and drilled hole insertion (Fig. 5). In order to estimate penetration depth for the first two methods, a typical sediment strength profile was assumed for normally consolidated fine-grained sediment (Fig. 6) based on data from cores up to $3 \mathrm{~m}$ long (Lee, 1973a). The core data were extrapolated to more than $60-\mathrm{m}$ subbottom depth using information gained from the Deep Sea Drilling Project (DSDP) (Lee, 1973b). The estimated undrained shear strength values have an accuracy of $\pm 50 \%$. Valent and Lee point out that although the typical soil profile can be used to determine an approximate penetration depth at many locations in the seafloor, substantial errors can be realized by indiscriminate use of an assumed strength profile. Markedly different strength profiles would result from environments that include heavily overconsolidated sediment caused by erosion or landsliding, cemented sediment, or coarse-grained material.

The sediment penetration resistance was obtained by numerically integrating the Poncelet equation after calculating or assuming a number of sediment properties: a frontal dynamic shear strength of twice the static undrained shear strength shown in Figure 6, (Migliore and Lee, 1971; True, 1975), the side-resistance equalled the frontal dynamic shear strength reduced by a factor of four-fifths (representing a strength sensitivity of 5), friction angle, and mass bulk density. Of the three methods proposed, Valent and Lee concluded that insertion into drilled holes is the best technique for high-level waste disposal because virtually any burial depth can be attained and the hole can be filled behind the waste.

In their discussion of sediment response to waste disposal in the seafloor, Karnes and others (1984) presented a comparis on of the models that other investigators have used to predict penetration. Beard (1977) used True's (1975) penetration model to compute the in situ shear strength of marine sediment using an acoustic Doppler penetrometer. He was able to determine undrained shear strength values within $\pm 30 \%$ of actual strength measurements obtained from core samples or in situ vane shear tests. Young (1977) impacted hard-wired penetrometers into ancient seabed sedimentary deposits near Wendover, Utah, at velocities ranging from 13 to $93 \mathrm{~m} / \mathrm{s}$. Young then constructed an empirical model to fit the field test results. Karnes and others (1984) compared Young's field data to True's (1975) data (Fig. 7) and found that the results diverged at deeper penetration depths. It should be noted that Young's (1977) test program did not simulate true seafloor conditions because the water column, which would have caused a shallower penetration due to increased drag effects (Karnes and others, 1984), was not accounted for. Karnes and others concluded that the free-fall projectiles under study might need additional thrust from boosters in order to achieve adequate penetration.

Brian Watt Associates, Inc. (1985) presented techniques for determining burial depth of objects into unlithified sediment from static penetration (impact velocity less than $0.9 \mathrm{~m} / \mathrm{s}$ ) for cohesive (grain size finer than or equal to fine silt) and cohesionless (grain size coarser than or equal to coarse silt) sediments for both shallow and deep penetrations (Fig. 3 ). If projectile impact velocities are between 0.9 and $120 \mathrm{~m} / \mathrm{s}$, a dynamic penetration method is used (Fig. 8). Overall, the dynamic technique is based 


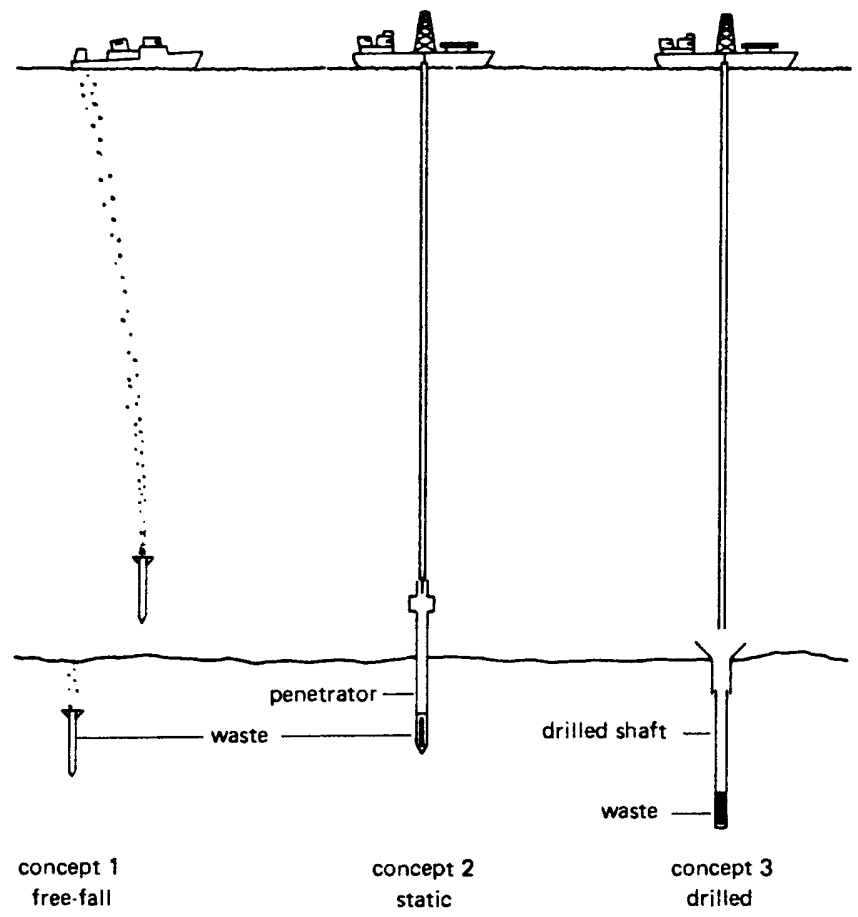

Figure 5. Methods of embedment presented by Valent and Lee (1976). 


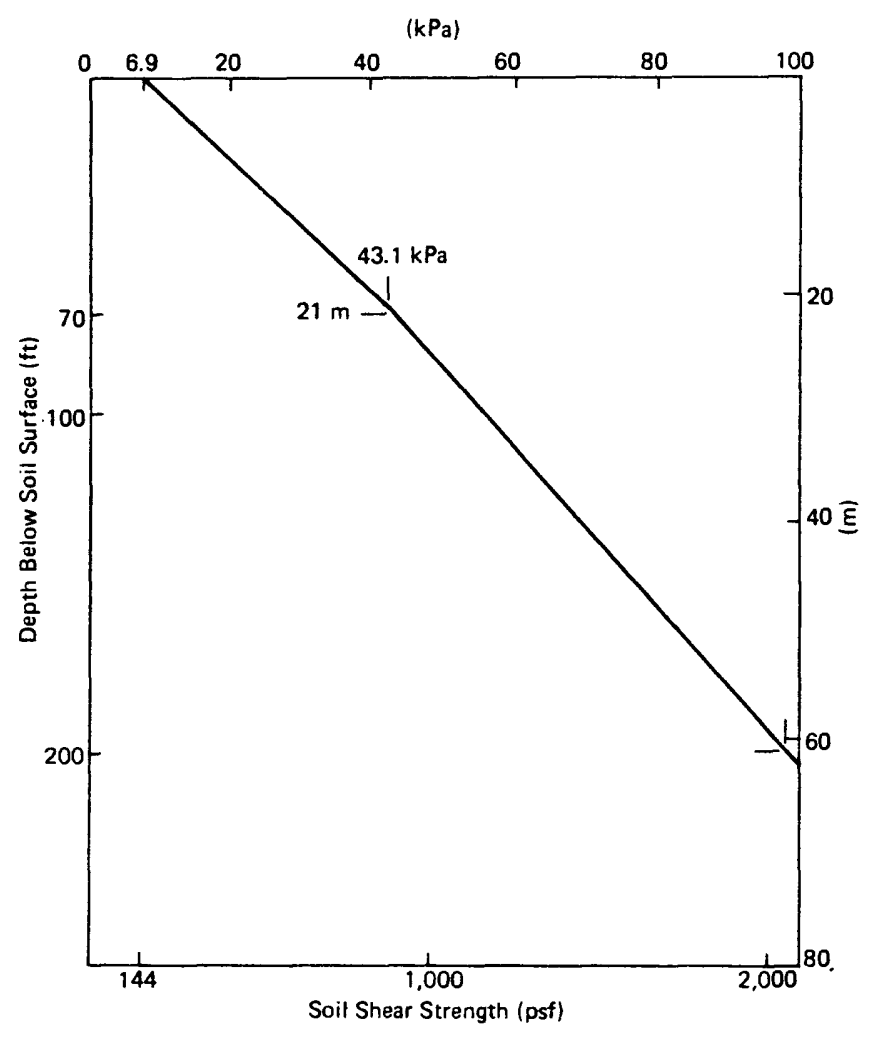

Figure 6. Assumed undrained shear strength profile for normally consolidated fine-grained sediment (Valent and Lee, 1976). 


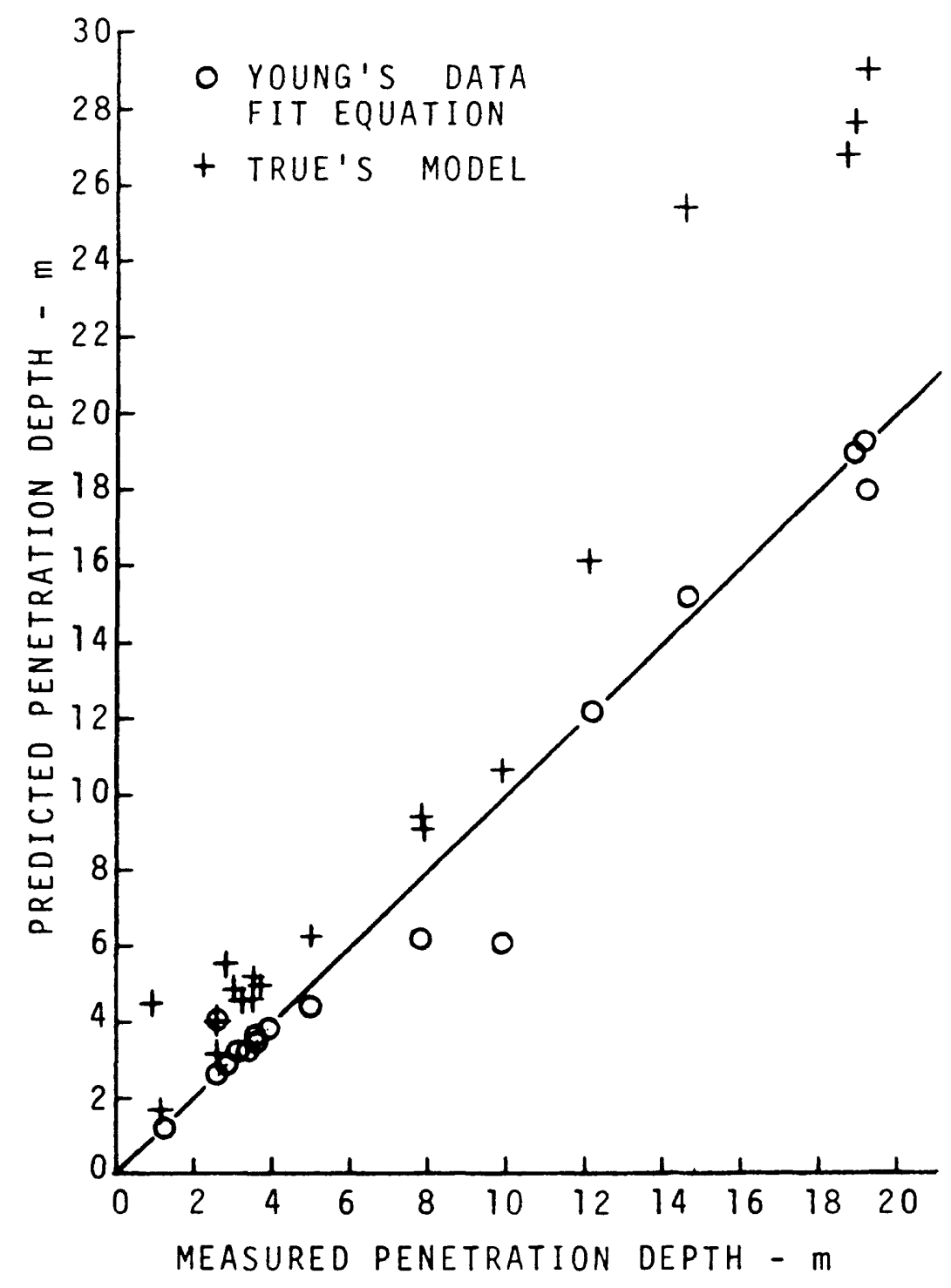

Figure 7. Comparison of two penetration models with the Wendover, Utah experimental results (Karnes and others, 1984). 


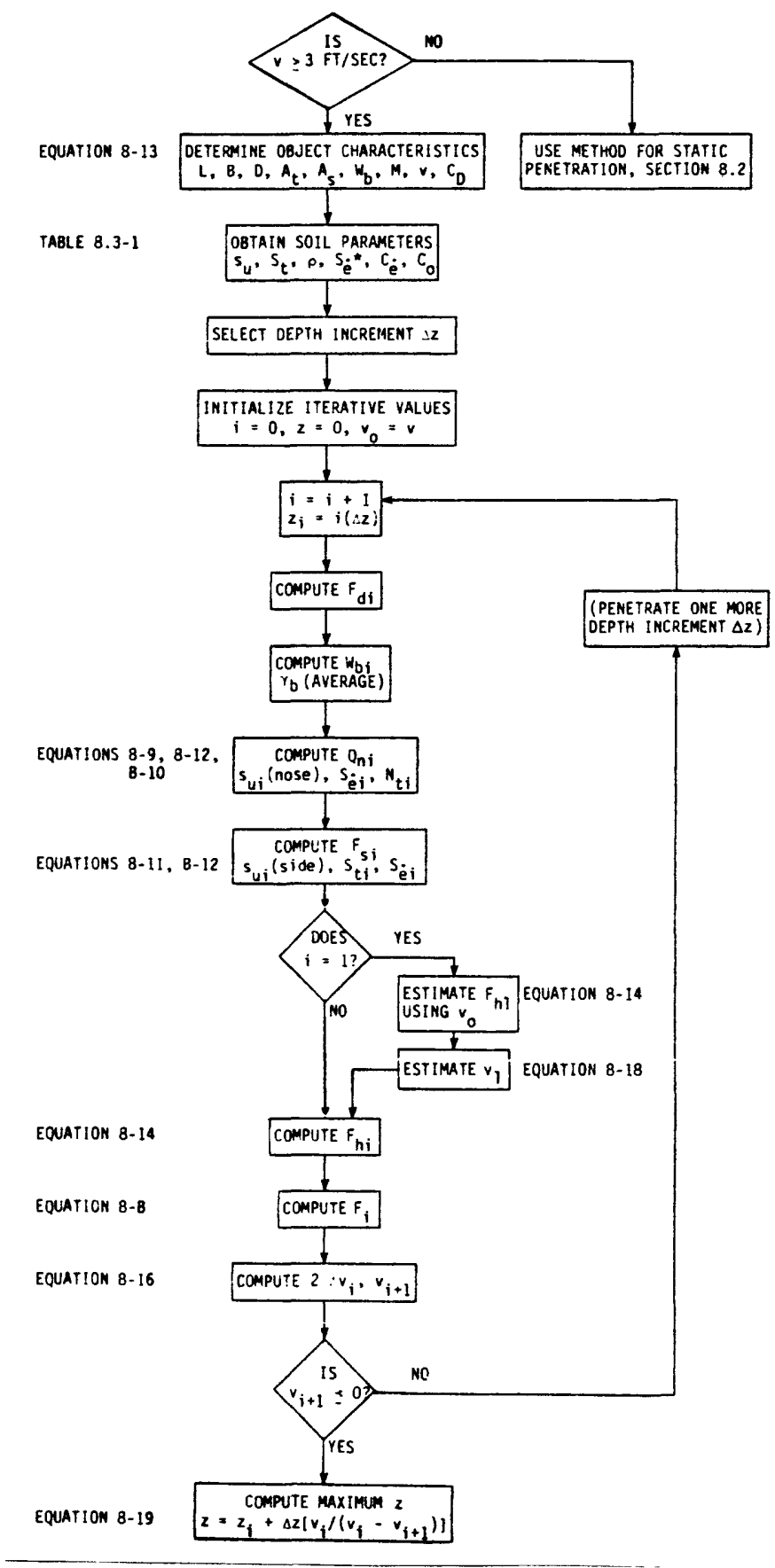

Figure 8. Flow chart of the calculation procedure for predicting dynamic penetration (Brian Watt Assoc., 1985). 
on the same principles as the static method, except strain rate effects on undrained shear strength, sediment sensitivity, and fluid drag components are included in the analysis.

Due to their high cost and complexity, relatively few detailed in situ test penetration programs have been conducted. Therefore, the prediction of subseabed penetration is still an inexact art, the accuracy of which is dependent on coupling a valid theory of penetrator dynamics with an adequate evaluation of required sediment properties.

\section{DYNAMIC HOLE CLOSURE}

The post-penetration behavior of the sediment has a crucial bearing on the feasibility of those methods of subseafloor disposal in which deep burial is required. Without complete hole closure, a conduit is formed from the waste cannister to the overlying water column, so that the site is unreliable and unsatisfactory for high-level waste disposal. However, the hole closure problem may not be an issue with regard to the disposal of low-level radioactive waste.

As a projectile rapidly penetrates the seafloor, the sediment directly in front of the projectile is initially pushed forward then remolded and quickly pushed laterally out of the path of the advancing cannister. The remolded sediment adheres to the sides or perimeter of the projectile and exerts a drag force that reduces the projectile's velocity. Behind the penetrator the sediment loses the projectile's lateral forces and is therefore able to elasto-plastically deform back into the space left by the penetrator. The projectile itself creates suction forces in its wake that may have a pronounced effect on sediment behavior and facilitate hole closure.

Methods of analyzing the complex nature of hole closure are still in the preliminary stages. Modeling the behavior of the sediment behind a penetrator or predicting the pressure gradient and flow of water into the open shaft formed by a projectile as it penetrates the seafloor are each alone problems that can be analyzed. However, the most difficulty in the analysis is experienced when the water $f l o w$ is coupled with the inelastic deformation of the sediment after passing of the penetrator (C. H. Karnes, Sandia National Laboratories, oral communication, Feb. 1986).

Pioneer work on the laboratory modeling of hole-closure under both dynamic and quasistatic penetration conditions was conducted at the University of Rhode Island (Bamford, 1980). Two types of tests (which were not performed under hydrostatic pressures representative of seafloor conditions) were performed: (1) projectiles were fired at high velocity from a compressed-air gun into a tank of remolded marine sediment and (2) probes were pushed at a rate of about $0.1 \mathrm{~m} / \mathrm{s}$ into similar sediment. The high velocity tests resulted in immediate hole closure, with only a small depression marking the site of penetration. In contrast during the slower penetration tests, the hole remained open until the walls gradually flowed in (Silva, 1977).

Although the laboratory work may have qualitatively illustrated sediment behavior during penetration, it did not portray valid hole-closure mechanisms because of boundary effects (A. J. Silva, University of Rhode Island, oral 
communication, Feb. 1986). Daws on and Chavez (1978) indicated that the holes that formed during dynamic penetration closed because of the reflection of pressure waves of $f$ the sides of the laboratory containment vessel.

Scientists at the Sandia National Laboratories in New Mexico, have investigated technologies with which to assess the hole-closure phenomenon. C. H. Karnes stated that during the initial stages of projectile penetration, the dynamic pressures created are two to three orders of magnitude larger than the shear strength of the sediment (Burdett and Karnes, 1986). Such a pressure differential would likely close off the hole and prevent any further flow of water in behind the penetrator. Once the hole closes near the seafloor, it will remain closed behind the projectile for the full depth of penetration. An approximate solution indicated that a seafloor velocity greater than $15 \mathrm{~m} / \mathrm{s}$ would be sufficient to close the hole (Dzwilewski and Karnes, 1981). Higher projectile velocities would simply close the hole faster.

A more rigorous solution coupled the water flow with sediment behavior, and used five hours of computation time (at a cost of about $\$ 5,000$ ) to model $160 \mathrm{~ms}$ of penetration time (Burchett and Canfield, 1981). That computer modeling (Fig. 9) showed that hole closure occurred approximately $35 \mathrm{~ms}$ after passage of the projectile traveling at a velocity of $40 \mathrm{~m} / \mathrm{s}$.

Work performed at Sandia National Laboratories indicates that penetration of a streamlined projectile into soft fine-grained seafloor sediment will be followed almost immediately by hole closure provided that a few conditions are met. The water depth must be great enough to prevent cavitation of seawater during penetration and to allow sufficient projectile velocity development (typically over $200 \mathrm{~m}$ ); and entrance velocities (about $40-45 \mathrm{~m} / \mathrm{s}$ ) must be high enough to generate strong suction forces behind the penetrator.

The Building Research Establishment (BRE) in England has been actively engaged in evaluating the feasibility of using free-fall penetrometers to dispose of high level radioactive waste. Data obtained from in situ tests that utilized a $12-\mathrm{kHz}$ Doppler penetrometer system indicated inconclusively that hole closure occurred behind the penetrator. Additionally, centrifuge experiments were performed at Cambridge University under BRE's direction. Although the tests were not run at high hydrostatic pressures, they nevertheless showed that more than one closure mechanism can occur. BRE is currently developing instrumentation (pore pressure transducers and load cells) to measure the in situ sediment force on the tail section of its penetrometers. Those data will better define whether or not hole closure occurs and, if it does, what mechanisms are responsible ( $T$. Freeman, Building Research Establishment, written communication, March 11, 1986).

The engineering studies task group (ESTG), is a multinational assembly of countries (including the United States, United Kingdom, Netherlands, Italy, and France) that is exploring methods for disposal of radioactive waste. The task group successfully performed in situ tests and coring operations in November 1986 off the coast of France with the intention of validating hole closure analyses (J. Hickerson, Sandia National Laboratories, oral communication, March 1987). Those trials are the most complete investigation of the hole closure phenomenon performed to date and will enable more accurate computer modelling to be executed in the future. 


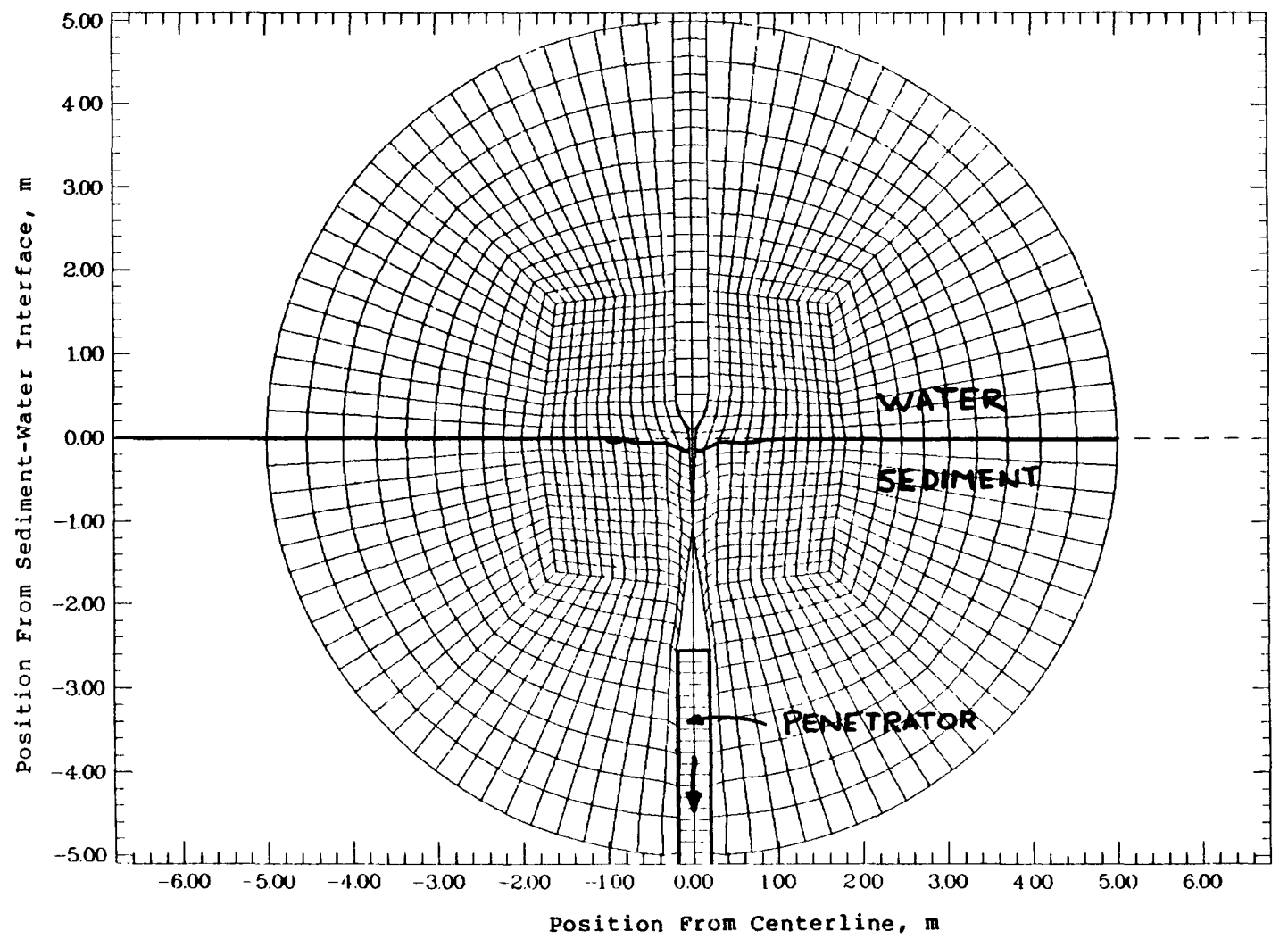

Figure 9. MARBLE computer simulation of an object penetrating the seafloor, illustrating subsequent hole closure (Burdett and Karnes, 1986). 
Two types of tests that have relevance to low-level waste disposal can be performed on marine sediment. The first group - water content, liquid limit determination, and plastic limit determination - characterizes the sediment and provides an indication, using empirical correlations, of the type of engineering behavior that can be expected. Typically the determinations are inexpensive to perform and require a minimum of laboratory soil-testing equipment. Although care must be exercised in running the tests, the methodologies are not complex.

The second type of test is performed to measure actual sediment properties for inclusion in penetration prediction analyses. Procedures range from those requiring a moderate amount of equipment and skill to perform, such as grain specific-gravity determination and vane shear strength measurement, to consolidation and triaxial strength tests that require expensive sophisticated test equipment, specially trained personnel, and days to perform. Specialized testing could also be performed to measure the undrained shear strength at high strain rates, sediment adhesion characteristics, and other parameters required as input to penetration prediction or computer modeling of hole closure.

These tests will probably be performed on core sections obtained from the abyssal plain, however, at least two problems exist with respect to coring. The first is that the coring operation always disturbs the sediment to some degree. The disturbance can be kept to acceptable levels by very careful planning, handling and storage of cores, and use of the most suitable types of coring equipment, but some minimal disturbance will occur. The second problem is that a gravity coring device may not penetrate to the required subbottom depth.

To better evaluate penetration potential at a particular site, a system similar to the Naval Civil Engineering Laboratory's Doppler penetrometer (Beard, 1977) could be used. Although that system could be too expensive for examination of low-level waste disposal sites, it might prove beneficial for high-level waste disposal. It presents in situ penetration test results directly, without additional coring and laboratory testing.

If in situ penetrometer tests are not performed some other means must be used to verify that unexpected obstructions, such as overconsolidated layers, are not present between the deepest core penetration level and the desired cannister penetration depth. Sediment could be obtained from a drilling program that utilizes a high-qualtiy push sampling technique or a geophysical method could be used to qualitatively show similarities between shallow subbottom sediment and underlying material. 


\section{ACKNOWLEDGEMENTS}

The author is grateful to the reviewers of this report, Homa Lee, Dennis 0 'Leary and Elizabeth Winget for their valuable comments and suggestions.

C. H. Karnes and J. Hickerson of Sandia National Laboratories, Albuquerque, N.M., T. Freeman of the Building Research Establishment, Watford, England, and A.J. Silva of the University of Rhode Island, Kingston, R.I. are thanked for their ideas and for providing information used in preparing this report.

Funding for this report was provided under Interagency Agreement DW 149 31699-01-0 with the U.S. Environmental Protection Agency. 
REFERENCES

Bamford, S. R., 1980, Hole closure behavior of marine sediments following projectile penetration: M. S. Thesis, Dept. of Ocean Engineering, University of Rhode Island, cited in Karnes and others, 1984.

Beard, R. M., 1977, Expendable Doppler penetrometer, a performance evaluation: Civil Engineering Laboratory Technical Report R-855, Port Hueneme, CA, $19 \mathrm{p}$.

Brian Watt Associates, Inc., 1985, Penetration of objects into the seafloor, chapter 8: in Rocker, $\operatorname{Kar} 1, \mathrm{Jr}$., ed., Handbook for marine geotechnica1 engineering: Naval Civil Engineering Laboratory, Port Hueneme, CA, 21 p.

Burchett, S. N. and Canfield, T., 1981, Hole closure calculations using HONDO II and MARBLE: Sub-Seabed Disposal Programme Annual Report, January to September, 1981, v. II: appendices, part 2 of 2, p. 301 , cited in Burdett and Karnes, 1986.

Burdett, J. R. F., and Karnes, C. H., 1986, Report of the fifth interim meeting of the seabed working group engineering studies task group: SAND 85-1563, Sandia National Laboratories, Albuquerque, NM, 46 p.

Bury, Mrc, 1985, The offshore disposal of radioactive waste by drilled emplacement: a feasibility study: London, Graham and Trotman, 175 p.

Chaney, R. C., Richards, A. F., and Murray, C. N., in press, Abyssal plains: potential sites for nuclear waste disposal: submitted to the Proceedings of the International Symposium on Environmental Geotechnology, Allent own, PA, April 21-24, 1986.

Daws on, P. R. and Chavez, P. F., 1978, Seabed waste disposal program: one-dimensional hole-closure simulation: SAND 78-1275, Sandia National Laborat ories, Albuquerque, NM, cited in Burdett and Karnes, 1986.

Dzwilewski, P. T. and Karnes, C. H., 1981, Dynamic hole closure behind a deep ocean sediment penetrator: Sub-Seabed Disposal Programme Annual Report, January to September, 1981, v. II: appendices, part 2 of 2, p. 335, cited in Burdett and Karnes, 1986.

Fischer, J.N., 1986, Hydrogeologic factors in the selection of shallow land burial sites for the disposal of low-level radioactive waste: U.S. Geological Survey Circular 973, 22p.

Heath, G.R., 1977, Barriers to radioactive waste migration: 0ceanus, v. 20, no. 1 , p. 26-30.

Hollister, C. D., 1977, The seabed option: Oceanus, v. 20, no. 1, p. 18-25.

Hunsaker, C.T. and Kelly, John, 1987, A watery grave: ASCE Civil Engineering, v. 57, no. 4, p. 52-55. 
Karnes, C. H., Daws on, P. R., Silva, A. J. and Brown, W. T., 1984, Sediment mechanical response due to emplacement of a waste canister: Marine Geotechnology, v. 5, nos. 3-4, p. 379-401. Previously published in Marine Technology '80 - Proceedings: The decade of the oceans, Marine Te chnol ogy Society.

Lee, H. J., 1973a, In-situ strength of seafloor soil determined from tests on partially disturbed cores: U.S. Naval Civil Engineering Laboratory, Technical Note $\mathrm{N}-1295,31 \mathrm{p}$.

Lee, H. J., 1973b, Measurements and estimates of engineering and other physical properties, Leg 19: in Creager, J., and others, Initial Reports of the Deep Sea Drilling Project, Vol. 19, p. 701-719.

Manheim, F.T. and Vine, Allyn, 1986, E.E.Z. may have waste disposal options: Ge otimes, v. 31 , no. 12 , p. 8-10.

Migliore, H. J., and Lee, H. J., 1971, Seafloor penetration tests: presentation and analysis of results: U.S. Naval Civil Engineering Laboratory, Technical Note N-1178, 59 p.

Richards, A., 1986, Abyssal plain faulting and its implications: in Burdett, J. R. F., and Karnes, C. H., 1986, Report of the fifth interim meeting of the seabed working group engineering studies task group: SAND 85-1563, Sandia National Laboratories, Albuquerque, NM, 46 p.

Schmid, W. E., 1969, The penetration of objects into the ocean bottom: Proceedings Civil Engineering in the Oceans II, American Society of Civil Engineers, Miami Beach, FL, p. 167-207.

Silva, A. J., 1977, Physical processes in deep-sea clays: Oceanus, v. 20, no.1, p. 31-40.

True, D. G., 1974, Rapid penetration into seafloor soils: Offshore Technology Paper No. 2095, Houst on, TX, p. 607-617.

True, D. G., 1975, Penetration of projectiles into seafloor soils: Civil Engineering Laboratory Technical Report R-822, Port Hueneme, CA, 47 p.

Valent, P. J. and Lee, H. J., 1976, Feasibility of subseafloor emplacement of nuclear waste: Marine geotechnology, v. 1, no. 4, p. 267-293.

Young, C. W., 1977, Memo to E. C. Rightley, subject, Wendover soil penetration test results: Sandia National Laboratories, No. 3. 